\title{
Description of Clinical Presentation and Outcome of Colonic Diverticular Disease in Makah Region, Series of 62 Patients
}

\author{
Suleiman Jastaniah ${ }^{1,2, *}$ \\ ${ }^{1}$ Department of General surgery, Faculty of Medicine, Umm Al-Qura University, Saudi Arabia \\ ${ }^{2}$ Department of General Surgery and Laparoscopic Surgery, Al-Noor Specialist Hospital, Saudi Arabia
}

*Corresponding author: Suleiman Jastaniah, Associate Professor, Department of General surgery, Faculty of Medicine, Umm Al-Qura University, Saudi Arabia, Tel: +966-505539003; E-mail: sa.jastaniah@hotmail.com

Received: 29 Jul, 2019 | Accepted: 16 Aug, 2019 | Published: 23 Aug, 2019

Citation: Jastaniah S (2019) Description of Clinical Presentation and Outcome of Colonic Diverticular Disease in Makah Region, Series of 62 Patients. J Surg Open Access 5(3) dx.doi.org/10.16966/2470-0991.187

Copyright: (c) 2019 Jastaniah S. This is an open-access article distributed under the terms of the Creative Commons Attribution License, which permits unrestricted use, distribution, and reproduction in any medium, provided the original author and source are credited.

\begin{abstract}
Introduction: Colonic diverticulosis is a common disease in western population and rare in Saudi Arabia. Although the true prevalence of diverticular disease is not known, few papers came from Saudi Arabia presenting their experience.

Aim: To determine the outcome of the disease, describe the clinical features, the role of CT-colonography in diagnosis, and the common site of the disease in Al-Noor specialist hospital in a holy city (Makah).

Patients and Methods: The records of all patients with a diagnosis of diverticular disease (diverticulosis and diverticulitis) during 5-year's period (Jan 2011-Dec 2015) were reviewed retrospectively. The demographic data of the patients with the diagnosis of diverticulosis or diverticulitis were collected, included age, sex, nationality, clinical presentation, tool of diagnosing the disease and the colonic site of the disease.

Results: A total of 62 patients were admitted to the surgical floor with a diagnosis of diverticular disease between Jan 2011 to Dec 2015 . Fifty one patients were Saudi and thirty two patients had bleeding per rectum. Three patients presented with a localized abscess and drained percutanously while another patient had abdominal mass. Colonoscopy was done for 28 patients, CT scan with oral and I.V contrast was done for 33 patients and virtual colonoscopy for 6 patients. None of our patients admitted with symptomatic un-complicated diverticular disease required surgical intervention in the first admission. Three patients readmitted, 2 with bleeding diverticulosis and the third one with a cute diverticulitis. There was no mortality in my series.

Conclusion: Colonic diverticulosis is increasing and the common clinical presentation is lower abdominal pain and massive lower gastrointestinal bleeding. The diagnosis is done during the acute presentation by CT scan or CT-colonography. Colonoscopy is diagnostic and therapeutic for lower Gl bleeding.
\end{abstract}

Keywords: Diverticular disease; Bleeding per rectum; Fecal fistula; CT-colonography

\section{Introduction}

Diverticular disease is one of the most common problems encountered by general surgeons and gastroenterologists [1]. Diverticular disease refers to complications that arise from colonic diverticulosis including lower gastrointestinal hemorrhage, inflammation, pain, abscess formation, fistula, strictures, perforation and death [2]. Colonic diverticulae are protrusions of the mucosa through the outer muscular layer to form narrow necked pouches. Colonic diverticular disease covers a wide clinical presentation: from an incidental finding to symptomatic uncomplicated disease to divericulitis with complications [3]. The prevalence of the disease is increasing in Saudi Arabia so I am focusing on the clinical presentation and the diagnosis in Makah region (Holy city) in one of the largest hospital in the area.

\section{Patients and Methods}

This is a retrospective study where the files of 62 patients diagnosed to have diverticular disease admitted to surgical floor in Al-Noor specialist hospital were analyzed according to age, gender and nationality. 51 patients were Saudi and 11 patients were non Saudi (Table 1). Clinical symptoms, investigations, line of treatment and complications were recorded.

\section{Results}

Colonic divertular disease was diagnosed in 62 patients 51 patients were Saudi and 11 patients were non-Saudi. (Table 1) (18 women, mean age $66 \pm 4)$. The symptomatic uncomplicated diverticular disease was diagnosed in 20 patients (32\%). Forty two patients admitted with symptomatic complicated disease (33 patients with 
Table 1: Total number of patients 62 .

\begin{tabular}{|c|l|l|l|}
\hline \multirow{2}{*}{ Age } & $<50$ years & 7 Patients & $11.30 \%$ \\
\cline { 2 - 4 } & $>50$ years & 55 Patients & $88.70 \%$ \\
\hline \multirow{2}{*}{ Sex } & Male & 44 Patients & $70.90 \%$ \\
\cline { 2 - 4 } & Female & 18 Patients & $29.10 \%$ \\
\hline \multirow{2}{*}{ Nationality } & Saudi & 51 Patients & $82.30 \%$ \\
\cline { 2 - 4 } & Non-Saudi & 11 Patients & $17.70 \%$ \\
\hline
\end{tabular}

rectal bleeding, 3 patients with abscess, 3 patients with fecal fistula and 3 patients with perforation). The male to female ratio was $3: 1$. The common symptom of diverticular disease in my series of patients was abdominal pain (39 patients) (Chart 1) and bleeding per rectum in $53.2 \%$ of patients (Chart 2). Only ten patients presented with fever. 28 patients had colonoscopy to diagnose the divericular disease or to stop the bleeding at the time of admission, where 33 patients had CT scan with oral and intravenous contrast, only 6 patients (10\%) had CTcolonography.

The thirty three patients admitted with rectal bleeding either required colonoscopy to stop the bleeding or the bleeding stopped spontaneously. The 3 patients admitted with diverticular abscess treated by antibiotics and percutanous drainage. The three patients admitted with diagnosis of perforation or fecal fistula required surgical intervention. The common site of diverticular disease was in sigmoid colon and the recto sigmoid part. There was no mortality in our series.

\section{Discussion}

Colonic diverticular disease is one of the common problems seen by general surgeons, colorectal surgeons and gastroenterologists $[1,2]$. This is the first paper comes from Al-Noor specialist hospital, one of the largest hospital in holy city Makah presenting clinical presentation and outcome of colonic diverticular disease. Colonic diverticular disease is one of the important causes of morbidity and mortality in the western countries [1-3]. William H Isbister reported 16 cases of diverticular disease within five years [4], while I reported 62 cases within five years which means that the incidence is increasing in Saudi Arabia. Colonic diverticular disease is prevalent and increasing not only in Western but also in Asian countries [5]. It is more common in males but in the western countries there is usually a slight preponderance of females (M:F ratio=1:1.2) [6]. The common site of diverticular disease is on the left side of the colon as in the Western and Asian countries [5]. The incidence of colonic diverticular disease is increasing with age as in Western countries [5-8]. Colonic diverticular bleeding is common presentation in our series (53\%), while it is $5-15 \%$ in Western countries [5,8], $32 \%$ in United States [6], and 2-10\% in Asia [9-11]. The bleeding is increased with age. Nagata $\mathrm{N}$, et al. [10] reported that diverticular bleeding was found in 427 of 28,192 (mean age 69.7 years) with a higher incidence in men (66.3\%). Kinjo K, et al. [11] also reported that patients with colonic diverticular bleeding were older male patients (more than 70 years old). Only 3 patients $(4.8 \%)$ presented with diverticular perforation whereas William $\mathrm{H}$ Isbister reported $(8 / 12)$ patients and in Western series this complication was much lower $[12,13]$ CT-colonography was helpful in diagnosis of 6 patients. Chabok A, et al. [14] claimed that CT-colonography is less painful and unpleasant and can be used for colonic investigation and follow up of diverticulitis. Dao HE, et al. [15] reported that the overall mortality rate among a total of 99,415 discharges for diverticular hemorrhage in the National Inpatients Sample in United States was 1.8\%. Another study in the Western countries reported that the mortality rate was 1.1-4.1 $[16,17]$. In our series there was no mortality.

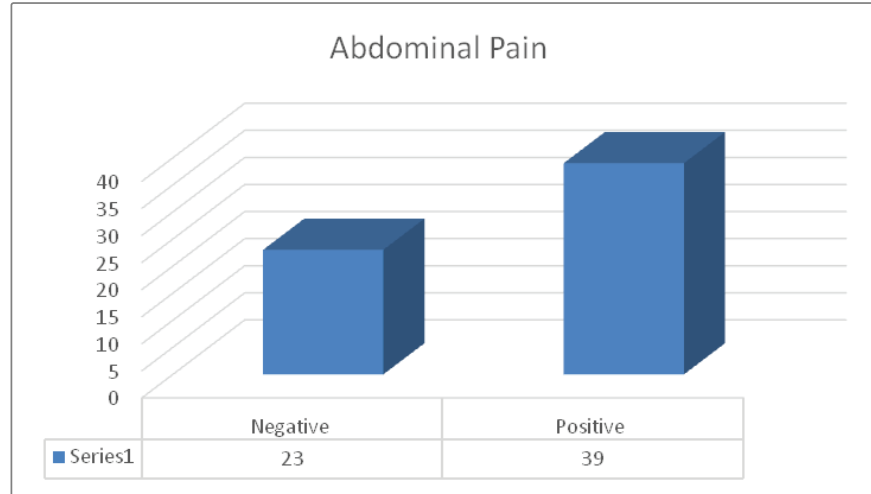

Chart 1: The common presenting symptoms in 62 patients.

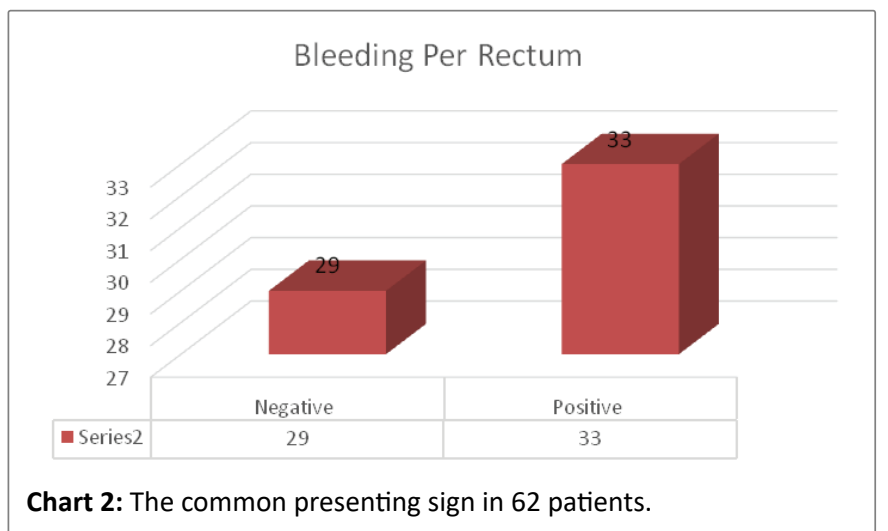

\section{Conclusion}

The prevalence of the diverticular disease in Kingdom of Saudi Arabia is increasing and the common presentation is as in the western countries abdominal pain. Complicated diverticular disease is also increasing. CT-colonography can be used for diagnosis and follow up of patients with diverticular disease. Early intervention by colonoscopy or radiology will improve the mortality. The surgeons and the gastroenterologists should mindful of the condition and its complications in Saudi Arabia.

A study of relation between food and diverticular disease in Saudi patients is needed in the future.

\section{Acknowledgment}

I would like to thank my colleagues in surgical department in AlNoor Specialist hospital for their permissions to collect the data of the patients.

\section{References}

1. Weizman AV, Nguyen GC (2011) Diverticular disease: Epidemiology and management. Can J Gastroenterol 25: 385-389.

2. Rodky GV, Welch CE (1984) Changing patterns in the surgical treatment of diverticular disease. Ann Surg 200: 466-478.

3. Kang JY, Melville D, Maxwell JD (2004) Epidemiology and management of diverticular disease of the colon. Drugs Aging 21: 211-228.

4. Niikura R, Nagata N, Shimbo T, Aoki T, Yamada A, et al. (2015) Natural history of bleeding risk in colonic diverticulosis patients: a long-term colonoscopy-based cohort study. Aliment Pharmacol Ther 41: 888889. 
5. Imaeda H, Hibi T (2018) The Burden of Diverticular Disease and its Complications: West versus East. Inflamm Intest Dis 3: 61-68.

6. Wheat CL, Strate LL (2016) Trends in Hospitalization for Diverticulitis and Diverticular Bleeding in the United States from 2000 to 2010. Clin Gastroenterol Hepatol 14: 96-103.

7. Yamamichi N, Shimamoto T, Takahashi Y, Sakaguchi Y, Kakimoto H, et al. (2015) Trend and Risk Factors of Diverticulosis in Japan: Age, Gender, and Lifestyle/Metabolic-Related Factors May Cooperatively Affect on the Colorectal Diverticula Formation. PLoS One 10: e0123688.

8. Imbembo AL, Bailey RW (1992) Diverticular disease of the colon. In: Sabiston DC Jr (eds) Textbook of Surgery. $14^{\text {th }}$ Edition, Churchill Livingstone 910.

9. Acosta JA, Grebenc ML, Doberneck RC, McCarthy JD, Fry DE (1992) Colonic diverticular disease in patients 40 years old or younger. Am Surg 58: 605-607.

10. Nagata N, Niikura R, Aoki T, Shimbo T, Itoh T, et al. (2014) Increase in colonic diverticulosis and diverticular hemorrhage in an aging society: lessons from a 9-year colonoscopic study of 28,192 patients in Japan. Int J Colorectal Dis 29: 379-385.
11. Kinjo K, Matsui T, Hisabe T, Ishihara H, Maki S, et al. (2016) Increase in colonic diverticular hemorrhage and confounding factors. World J Gastrointest Pharmacol Ther 7: 440-446.

12. Isbister WH, Prasad J (1995) Surgical management of diverticular disease. Coloproctology 17: 263-272.

13. Parks TG (1975) Natural history of diverticular disease of the colon. Clin Gastroenterol 4: 53-69.

14. Chabok A, Smedh K, Nilsson S, Stenson M, Pahlman L (2013) CT-colonography in the follow-up of acute diverticulitis: patient acceptance and diagnostic accuracy. Scand J Gastroenterol 48: 979986.

15. Dao HE, Miller PE, Lee JH, Kermani R, Hackford AW (2013) Transfer status is a risk factor for increased in-hospital mortality in patients with diverticular hemorrhage. Int J Colorectal Dis 28: 273-276.

16. Aytac E, Stocchi L, Gorgun E, Ozuner G (2014) Risk of recurrence and long-term outcomes after colonic diverticular bleeding. Int J Colorectal Dis 29: 373-378.

17. Poncet G, Heluwaert F, Voirin D, Bonaz B, Faucheron JL (2010) Natural history of acute colonic diverticular bleeding: a prospective study in 133 consecutive patients. Aliment Pharmacol Ther 32: 466471 